\title{
Clustering of the $\mathrm{K}^{+}$channel GORK of Arabidopsis parallels its gating by extracellular $\mathrm{K}^{+}$
}

\author{
Cornelia Eisenach ${ }^{\dagger}$, Maria Papanatsiou, Ellin-Kristina Hillert and Michael R. Blatt* \\ Laboratory of Plant Physiology and Biophysics, Institute of Molecular, Cell and Systems Biology, University of Glasgow, \\ Bower Building, Glasgow G12 80Q, UK
}

Received 10 November 2013; revised 18 January 2014; accepted 22 January 2014; published online 12 February 2014.

*For correspondence (e-mail Michael.Blatt@glasgow.ac.uk).

'Present address: Institute of Plant Biology, University of Zurich, $\mathrm{CH}-8008$ Zurich, Switzerland.

\begin{abstract}
SUMMARY
GORK is the only outward-rectifying Kv-like $\mathrm{K}^{+}$channel expressed in guard cells. Its activity is tightly regulated to facilitate $\mathrm{K}^{+}$efflux for stomatal closure and is elevated in ABA in parallel with suppression of the activity of the inward-rectifying $\mathrm{K}^{+}$channel KAT1. Whereas the population of KAT1 is subject to regulated traffic to and from the plasma membrane, nothing is known about GORK, its distribution and traffic in vivo. We have used transformations with fluorescently-tagged GORK to explore its characteristics in tobacco epidermis and Arabidopsis guard cells. These studies showed that GORK assembles in puncta that reversibly dissociated as a function of the external $\mathrm{K}^{+}$concentration. Puncta dissociation parallelled the gating dependence of GORK, the speed of response consistent with the rapidity of channel gating response to changes in the external ionic conditions. Dissociation was also suppressed by the $\mathrm{K}^{+}$channel blocker $\mathrm{Ba}^{2+}$. By contrast, confocal and protein biochemical analysis failed to uncover substantial exo- and endocytotic traffic of the channel. Gating of GORK is displaced to more positive voltages with external $\mathrm{K}^{+}$, a characteristic that ensures the channel facilitates only $\mathrm{K}^{+}$efflux regardless of the external cation concentration. GORK conductance is also enhanced by external $\mathrm{K}^{+}$above $1 \mathrm{~mm}$. We suggest that GORK clustering in puncta is related to its gating and conductance, and reflects associated conformational changes and (de)stabilisation of the channel protein, possibly as a platform for transmission and coordination of channel gating in response to external $\mathrm{K}^{+}$.
\end{abstract}

Keywords: GORK $\mathrm{K}^{+}$channel - outward-rectifying, membrane vesicle traffic, plasma membrane, confocal microscopy, $\mathrm{K}^{+}$concentration - extracellular, channel gating - $\mathrm{K}^{+}$-dependent, Arabidopsis.

\section{INTRODUCTION}

Control of membrane transport is central to solute flux for stomatal regulation. Membrane transport of the predominant, osmotically-active ion, $\mathrm{K}^{+}$, is of particular importance and is mediated largely by voltage-dependent $\mathrm{K}^{+}$channels. Inward-rectifying $\mathrm{K}^{+}$channels mediate $\mathrm{K}^{+}$uptake during stomatal opening, while outward-rectifying $\mathrm{K}^{+}$channels mediate its loss during stomatal closing (Blatt and Thiel, 1993; Blatt, 2000; Lebaudy et al., 2007; Dreyer and Blatt, 2009). In Arabidopsis, the former are dominated by the inward-rectifying $\mathrm{K}^{+}$channel KAT1, which is highlyexpressed in guard cells, and to a lesser extent the related channel KAT2. $\mathrm{K}^{+}$efflux across the plasma membrane is facilitated by GORK, which is the only outward rectifying $\mathrm{K}^{+}$-channel known to be expressed in the guard cells (Ache et al., 2000; Hosy et al., 2003; Dreyer and Blatt, 2009).
KAT1 and GORK belong to the Kv superfamily of voltage-gated ion channels that are found also in archaea insects and mammals. These channels open and close, a process referred to as 'gating', in response to membrane voltage. Outward-rectifying $\mathrm{K}^{+}$channels of plants, including GORK, also gate in response to the extracellular $\mathrm{K}^{+}$ concentration. Increasing the extracellular $\mathrm{K}^{+}$concentration displaces the voltage-dependence of gating to more positive voltages in parallel with the equilibrium voltage for $\mathrm{K}^{+}$ $\left(E_{\mathrm{K}}\right)$ and, at concentrations above $1 \mathrm{~mm}$, increases the max imum ensemble conductance (Blatt, 1988; Blatt and Gradmann, 1997; Ache et al., 2000; Johansson et al., 2006). Potassium is the most abundant ionic species in plants; its concentration outside, and its equilibrium, often dominates the membrane voltage in plants. Gating by extracellular $\mathrm{K}^{+}$ therefore ensures that these channels activate at a voltage 
relative to $E_{\mathrm{K}}$ and adjusts $\mathrm{K}^{+}$efflux through the channels in a compensatory manner across a wide range of $\mathrm{K}^{+}$concentrations (Blatt, 1988; Blatt and Gradmann, 1997).

The activities of guard cell $\mathrm{K}^{+}$channels are subject to a number of regulatory stimuli, including hormones such as abscisic acid (ABA) (Blatt, 2000; Blatt et al., 2007; Kim et al., 2010; Roelfsema and Hedrich, 2010), auxin (Thiel et al., 1993; Blatt and Thiel, 1994; Bauly et al., 2000), metabolites (Hedrich et al., 2001; Wang and Blatt, 2011), and pathogen elicitors (Blatt et al., 1999). Many of these stimuli act through intermediates of cytosolic-free $\left[\mathrm{Ca}^{2+}\right]$ $\left(\left[\mathrm{Ca}^{2+}\right]_{\mathrm{i}}\right), \mathrm{pH}$ and protein (de-)phosphorylation (Blatt et al., 1990; Blatt and Grabov, 1999; Blatt, 2000; Kim et al., 2010). Channel responses to these intermediates are usually very rapid and are underpinned by changes in channel gating, but over longer time periods can extend to membrane vesicle traffic and changes in channel population at the membrane. Much less is known of the scope of channel regulation by vesicle traffic or its regulation. To date, only the KAT1 $\mathrm{K}^{+}$channel has been studied in any detail (Hurst et al., 2004; Meckel et al., 2005; Sutter et al., 2006, 2007; Eisenach et al., 2012). KAT1 is localised at the plasma membrane in punctate domains from which $A B A$ and $\left[\mathrm{Ca}^{2+}\right]_{\mathrm{i}}$ trigger its endocytosis. Its recycling to the plasma membrane depends on the vesicle-trafficking protein SYP121 (=SYR1/PEN1) (Leyman et al., 1999) and underpins the phenomenon of so-called 'programmed closure' of stomata (Eisenach et al., 2012). By contrast, nothing is known of the localisation, distribution and trafficking of the outward-rectifying $\mathrm{K}^{+}$channels, including GORK. Here we show that GORK is localised in discrete puncta at the plasma membrane that are similar to, but distinct from, those reported previously for KAT1-GFP. Unexpectedly, GORK-GFP puncta proved to be insensitive to $A B A$ or the presence of SYP121, but channel distribution was affected by increasing external $\mathrm{K}^{+}$concentrations in parallel with the dependence of channel gating on the cation. We propose that the gating of GORK with external $\mathrm{K}^{+}$concentration is associated with a re-organisation of the channel proteins in clusters within the plane of the plasma membrane.

\section{RESULTS}

\section{GORK-GFP is a functional outward rectifying $\mathrm{K}^{+}$channel that localises in puncta}

We generated GORK-GFP constructs for expression under the control of the Ubiquitin-10 gene promoter to give moderate over-expression in vivo (Grefen et al., 2010b) and verified functionality of the recombinant protein after expression in Xenopus oocytes. Oocytes injected with GORK-GFP cRNA showed an outward current (Figure S1) when clamped to voltages positive of $E_{K^{\prime}}$, with current relaxations typical of the GORK channel and block by TEA ${ }^{+}$ (Figure S2). Relative conductances $\left(G / G_{\max }\right)$ were well-fitted to a Boltzmann function (see Figure S1) with a half-maximal activation voltage $\left(V_{1 / 2}\right)$ that was displaced in parallel with $E_{K}$, much as has previously been shown for GORK (Ache et al., 2000), the outward-rectifier of Vicia (Blatt, 1988; Blatt and Gradmann, 1997) and for SKOR, the close homolog of the GORK $\mathrm{K}^{+}$channel (Johansson et al., 2006).

We generated stable transformants with GORK-GFP in wild-type Arabidopsis and in the syp121 mutant that lacks the vesicle-trafficking (SNARE) protein SYP121 (=SYR1/ PEN1) (Leyman et al., 1999) and is known to affect $\mathrm{K}^{+}$channel traffic and function (Honsbein et al., 2009; Grefen et al., 2010a; Eisenach et al., 2012). Leaves of $T_{2}$ and $T_{3}$ lines from three independent transformation events were selected; in every case GORK-GFP fluorescence appeared in puncta around the cell periphery (Figure 1), both in wildtype and syp121 mutant backgrounds. Fluorescence was detected in epidermal cells and guard cells (Figure 1a), distinct from chloroplast fluorescence (Figure 1b), and was localised to the cell periphery (Figure 1c-j). Intracellular GORK-GFP signals were observed in $7 \%(n=72)$ of stomata, mostly in very young, developing tissue. Analysis of puncta size yielded diameters of of $0.63 \pm 0.01 \mu \mathrm{m}(n=97)$ that were normally distributed and well-removed from the diffraction limit near $300 \mathrm{~nm}$ (Figure 1k). These dimensions compare favourably with the mean diameter of $0.5 \mu \mathrm{m}$ observed for microdomains formed by KAT1-GFP in tobacco (Sutter et al., 2006). Although similar in size and distribution, the puncta formed by RFP-tagged GORK did not co-localize (Figures S3 and S4) with puncta formed by the GFP-tagged KAT1 $\mathrm{K}^{+}$channel (Sutter et al., 2006, 2007). When expressed in tobacco, fluorescence was occasionally observed within epidermal cells; nonetheless, after plasmolysis GORK-GFP fluorescence was observed in Hechtian strands (Figure S5, arrows), indicating that the punctate structures were localised to the plasma membrane.

\section{GORK-GFP puncta are sensitive to the external $\mathrm{KCI}$ concentration}

KAT1-GFP is internalised from the plasma membrane following application of ABA (Sutter et al., 2007), and by treatments known to elevate $\left[\mathrm{Ca}^{2+}\right]_{\mathrm{i}}$ (Grabov and Blatt, 1998), studies showing its recycling by SYP121-mediated traffic underpins programmed stomatal closure (Leyman et al., 1999; Eisenach et al., 2012). We used the treatments to elevate $\left[\mathrm{Ca}^{2+}\right]_{\mathrm{i}}$, anticipating that GORK traffic would complement that of the KAT1 channel. Intact leaves were incubated for $2 \mathrm{~h}$ under light after infiltration with Depolarising Buffer (DB) containing $100 \mathrm{~mm} \mathrm{KCl}$ and $0 \mathrm{CaCl}_{2}$ to open stomata, and stomatal closure was induced by exchange with Hyperpolarising Buffer (HB) containing $0.1 \mathrm{~mm} \mathrm{KCl}$ and $10 \mathrm{~mm} \mathrm{CaCl}_{2}$ (Eisenach et al., 2012). We found that GORK-GFP did not internalise following $\mathrm{HB}$ treatment, unlike KAT1 (Eisenach et al., 2012). Instead, the 

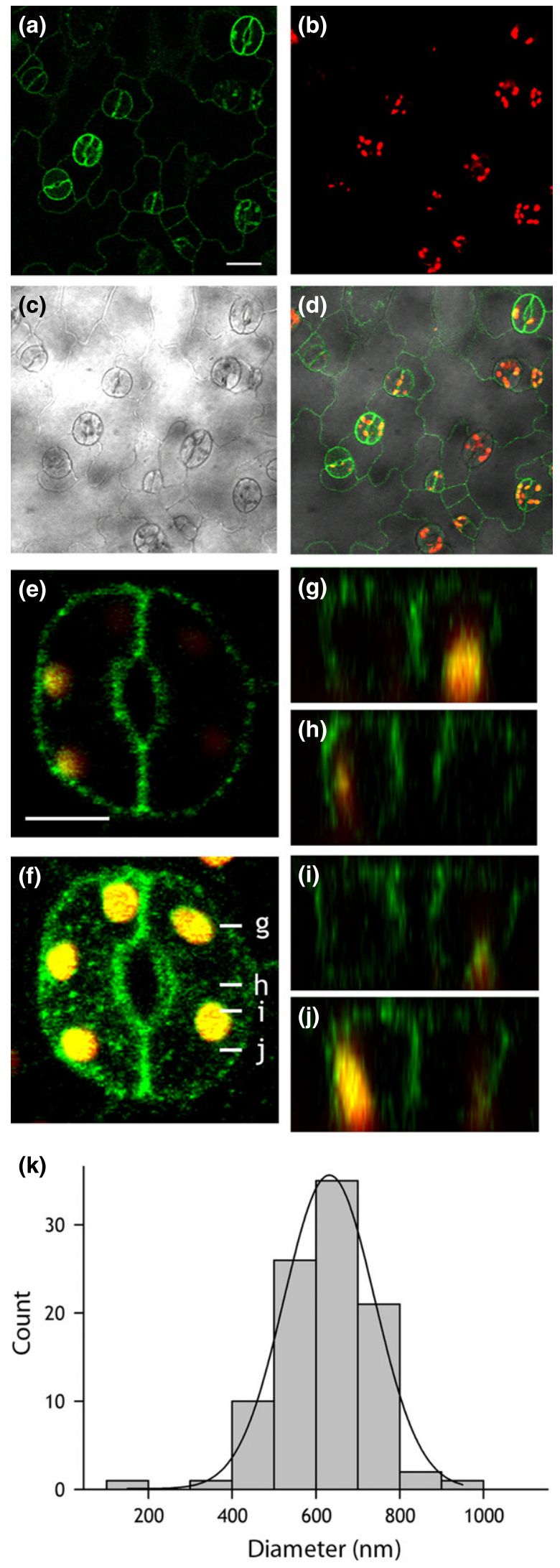

Figure 1. GORK localises in puncta at the periphery of Arabidopsis guard cells and epidermal cells.

(a-d) Confocal fluorescence images of GORK-GFP (green, a), chlorophyll fluorescence (red, b), bright field (c) and the corresponding overlay image (d) from the epidermis of an Arabidopsis leaf expressing pUBO10::GORK-GFP. Scale bar, $20 \mu \mathrm{m}$.

(e) Lateral optical section through a single pair of Arabidopsis guard cells showing punctate distribution of GORK-GFP (green) and chloroplasts (yellow). Scale bar, $5 \mu \mathrm{m}$.

(f) $3 \mathrm{D}$ projection of the same guard cell pair in (e) reconstructed from a $z$-stack collected at intervals of $0.8 \mu \mathrm{m}$.

(g-j) Z-plane sections derived from (f) at the positions indicated by white lines in (f).

(k) Histogram analysis of the diameters of GORK-GFP puncta. Data were fitted to a gaussian function (solid line), indicating a normal distribution of diameters about a mean of $632 \pm 1 \mathrm{~nm}$.

punctate distribution of GORK-GFP was lost in DB, the fluorescence redistributing around the cell periphery. This process was fully reversible on transfer back to HB and was evident in both wild-type and syp121 mutant Arabidopsis. However, treatments with ABA had no effect on GORKGFP distribution (Figures S6 and S7). We reasoned that the changes in the punctate distribution observed between DB and $\mathrm{HB}$ were likely to be related to the ionic content of the buffer rather than to $\mathrm{Ca}^{2+}$ or $\mathrm{ABA}$ signalling per se. We repeated the experiment with solutions of $100 \mathrm{mM} \mathrm{KCl}$ and $0.1 \mathrm{~mm} \mathrm{KCl}$ alone. Again, we found, GORK-GFP puncta were clearly visible in $0.1 \mathrm{~mm} \mathrm{KCl}$ (Figure 2a,b) but, in the
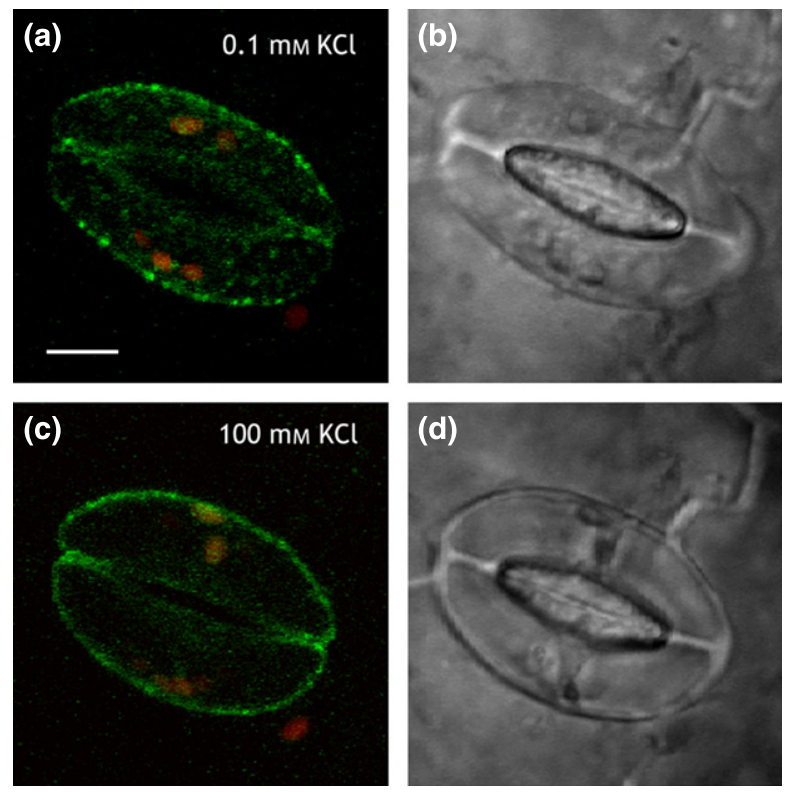

Figure 2. GORK-GFP fluorescence is punctate in $0.1 \mathrm{~mm} \mathrm{KCl}$, but is diffuse in $100 \mathrm{~mm} \mathrm{KCl}$.

GORK-GFP fluorescence (a, c) and brightfield images (b, d) in a pair of guard cells in $0.1 \mathrm{~mm} \mathrm{KCl}(\mathrm{a}, \mathrm{b})$ and after transfer to $100 \mathrm{~mm} \mathrm{KCl}(\mathrm{c}, \mathrm{d})$. Scale bar, $5 \mu \mathrm{m}$. Images in (a) and (c) are overlaid, 3D projections of GORK-GFP (green) and chloroplast (red) fluorescence from z-stacks taken at intervals of $0.7 \mu \mathrm{m}$. Equivalent results were obtained with Hyperpolarising and Depolarising Buffers (see text). 
same guard cells, the punctate distribution was lost when the external $\mathrm{KCl}$ concentration was raised to $100 \mathrm{~mm}$ (Figure $2 \mathrm{c}, \mathrm{d})$. To exclude an effect of osmotic strength, we repeated these experiments with $0.1 \mathrm{~mm} \mathrm{KCl}$ including Mannitol to adjust the osmotic strength to that of the $100 \mathrm{~mm} \mathrm{KCl}(200 \pm 10 \mathrm{mOsmol})$. No difference in GORKGFP distribution was observed between treatments with and without mannitol, thus excluding osmotic effects as the explanation for the changing GORK-GFP distribution.

\section{GORK-GFP redistribution is not associated with endocytic traffic}

The dissolution of KAT1 puncta is marked by a substantial increase in mobility and endocytosis of the channels (Sutter et al., 2007; Eisenach et al., 2012). To determine whether GORK-GFP dispersal was similarly associated with endocytosis from the plasma membrane, we first examined the mobility of GORK-GFP by time-lapse and by fluorescence recovery after photobleaching (FRAP) analysis. Figure 3 illustrates one of eight independent time-lapse experiments with GORK-GFP puncta identified at the stomatal surface in tangential scans (Figure 3a,b). Kymographic analysis (Figure 3c) yielded no evidence of lateral movement. We used FRAP analysis in Arabidopsis to determine the recovery of fluorescence at the cell periphery, calculating the mobile fraction of GORK-GFP fluorescence from the signal recovery. GORK-GFP was photobleached locally at the periphery of guard cells preincubated in 0.1 and $100 \mathrm{~mm} \mathrm{KCl}$, and its recovery within the photobleached regions was monitored. Figure 3(d) summarizes the result of 12 independent experiments. FRAP analysis yielded similar results in 0.1 and $100 \mathrm{~mm} \mathrm{KCl}$ : fluorescence recovered with a mean halftime of $36 \pm 4 \mathrm{sec}$ in $0.1 \mathrm{~mm} \mathrm{KCl}$ and $28 \pm 7 \mathrm{sec}$ in $100 \mathrm{~mm} \mathrm{KCl}$, a difference that was not significant at the $P<0.05$ level. Additionally, in both $\mathrm{KCl}$ concentrations the GORK-GFP signal was predominantly non-mobile, with a mobile fraction of $9 \pm 1 \%$ in $100 \mathrm{~mm} \mathrm{KCl}$ and of $14 \pm 6 \%$ in $0.1 \mathrm{~mm} \mathrm{KCl}$. Again, the difference was not statistically significant at the $P<0.05$ level.

We used aqueous, two-phase partitioning as an independent test for GORK redistribution between the plasma membrane and endomembranes, including endocytotic vesicles (Sutter et al., 2006, 2007; Honsbein et al., 2009). GORK polyclonal antibodies were raised against a synthetic peptide corresponding to a GORK-specific N-terminal amino-acid sequence (Figure S8). The antibodies were purified and verified for specificity in detecting GORK after immunoblotting. Figure 4(a) shows an immunoblot of soluble (S) and microsomal (M) protein fractions probed with $\alpha$ GORK antibody and the pre-immune serum. The antibody detected a band near the $80 \mathrm{kDa}$ marker in the microsomal protein fraction and close to the $93.8 \mathrm{kDa}$ predicted for GORK. Analysis of microsomal proteins extracts from
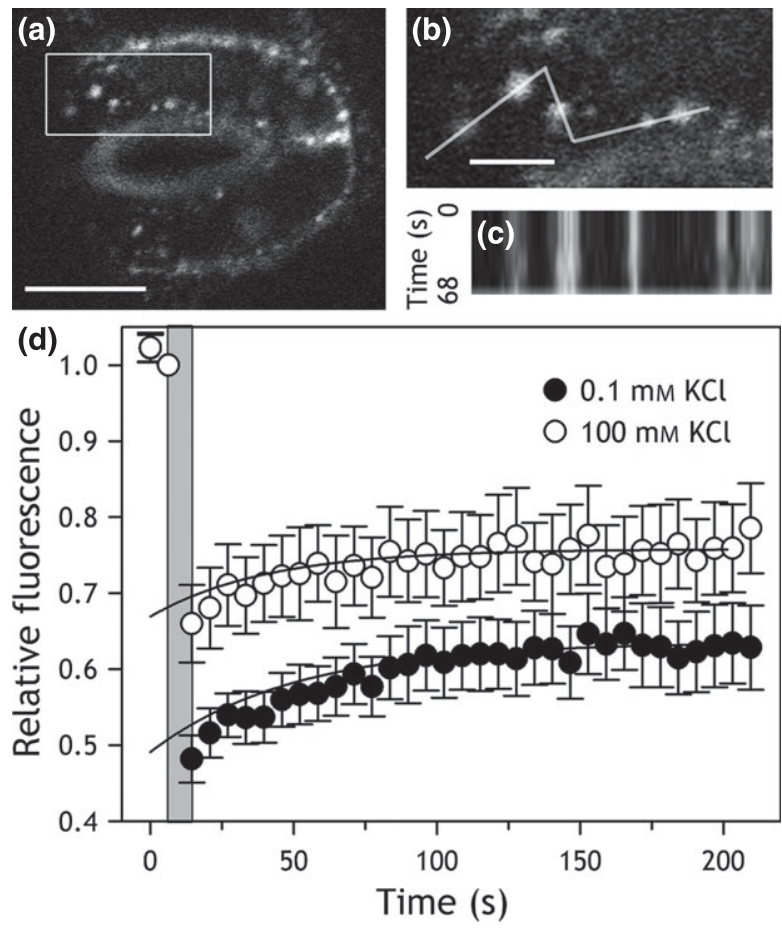

Figure 3. The macroscopic mobility of GORK-GFP at the cell periphery is not affected by extracellular $\mathrm{KCl}$ concentration.

(a) Tangential section of a guard cell pair with GORK-GFP puncta in $0.1 \mathrm{~mm}$ $\mathrm{KCl}$. Scale bar, $5 \mu \mathrm{m}$.

(b) Close-up of the boxed region in (a) with the linescan for kymographic analysis as indicated. Scale bar, $2 \mu \mathrm{m}$.

(c) Kymograph over the linescan in (b) collected over a time interval of $68 \mathrm{sec}$. The $x$-axis corresponds to the linescan dimension and the $y$-axis corresponds to time. The analysis shows that GORK-GFP is positionally stable over this time period.

(d) Fluorescence recovery after photobleaching (FRAP) of the GORK-GFP recorded from guard cells in $0.1 \mathrm{~mm} \mathrm{KCl}$ (closed circles, $n=12$ ) and in $100 \mathrm{~mm} \mathrm{KCl}$ (open circles, $n=11$ ). Fluorescence was normalised to the signals at the start of the experiments after correcting for fluorescence decay (Sutter et al., 2006, 2007) and fluorescence recoveries after the photobleaching period (grey) were fitted to a single exponential function (solid lines) to derive halftimes and amplitudes for recovery.

wild-type plants, a transgenic GORK-GFP overexpressing line probed with $\alpha \mathrm{GFP}$ antibody, and the gork mutant confirmed this band as the GORK protein (Figure 4b).

We separated plasma membrane and endomembrane fractions after pretreatments of leaf tissues with 0.1 and $100 \mathrm{~mm} \mathrm{KCl}$. Figure 4(c) shows an immunoblot of plasma membrane and endomembrane protein fractions from one of two independent experiments, each yielding similar results. Equal loading between samples of plasma and of endomembrane fractions was verified by Ponceau staining and purity was confirmed by probing against the plasma membrane marker AHA3 (Pardo and Serrano, 1989) and the endomembrane marker Sec61 (Yuasa et al., 2005). GORK bands of comparable intensity were observed in plasma membrane fractions irrespective of pretreatments with 0.1 and $100 \mathrm{~mm} \mathrm{KCl}$ (Figure 4c, left). GORK bands 


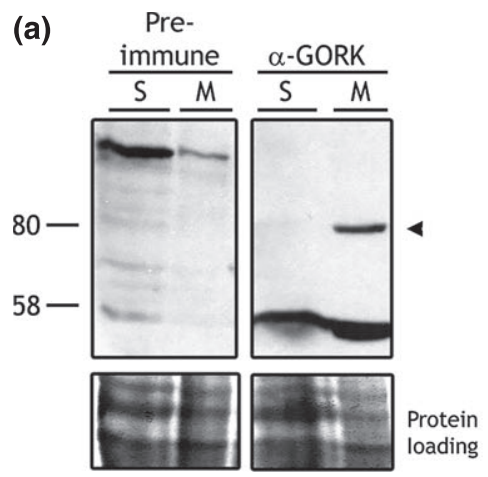

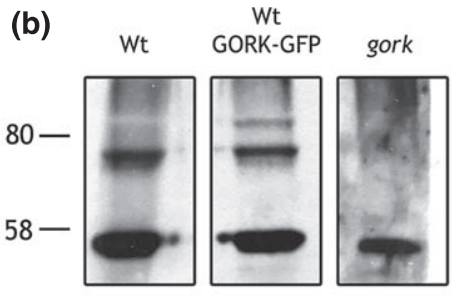

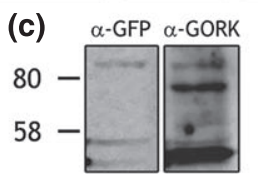

(d)

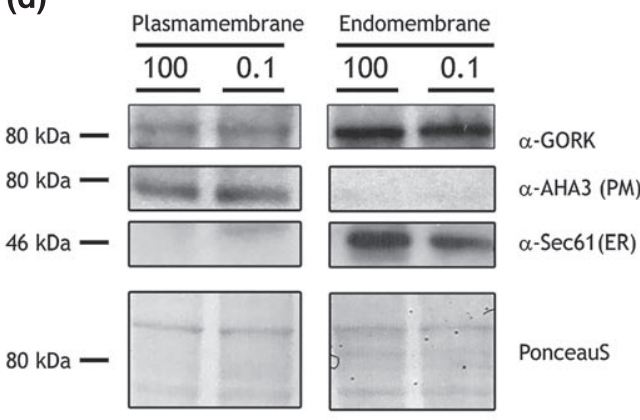

Figure 4. $\alpha$ GORK antibody raised to an N-terminal peptide shows no substantial redistribution of the $\mathrm{K}^{+}$channel between plasma membrane and endomembranes in Arabidopsis.

(a) Immunoblot (top) and Ponecau S stain (bottom) of wild-type Arabidopsis soluble (S) and microsomal (M) protein fractions, probed either with pre-immune serum (left) and with the purified $\alpha$ GORK antibody (right). The $\alpha$ GORK antibody uniquely detected a single band around $80 \mathrm{kDa}$ in the microsomal fraction (arrowhead, right).

(b) Immunoblot of Arabidopsis microsomal fractions from wild type (Wt), a transgenic line expressing GORK-GFP (GORK-GFP), and the gork null mutant. Note the double band in the GORK-GFP fraction corresponds to endogenous GORK and recombinant GORK-GFP. The $80 \mathrm{kDa}$ band is missing from the gork mutant. The lower intensity of the GORK-GFP band probably is a consequence of co-suppression of the transgene.

(c) Immunoblot of Arabidopsis microsomal fractions from a transgenic line expressing GORK-GFP and probed with $\alpha$ GFP antibody. Note that the antibody detects a specific band above $80 \mathrm{kDa}$. An additional band is evident on stripping and reprobing with $\alpha \mathrm{GORK}$ antibody, consistent with the presence of the native channel.

(d) Endogenous GORK is not affected by the external buffer or $\mathrm{KCl}$ concentration.

Immunoblot and PonceauS stain of plasma membrane and endomembrane protein fractions from aqueous two-phase partitioning of Arabidopsis leaves pretreated with either 0.1 or $100 \mathrm{mM} \mathrm{KCl}(0.1$ and 100, indicated above). Molecular weights (left) and staining or antibody used for detection (right) are indicated. PonceauS stain of the membrane (bottom) shows equal protein loading within each gel. The membrane was probed with $\alpha \mathrm{GORK}$ antibody ( $\alpha \mathrm{GORK}$ ) before stripping and re-probing, first with an antibody against the plasma membrane $\mathrm{H}^{+}$-ATPase AHA3 ( $\alpha$ AHA3), and an antibody against the ER-localised translocon Sec61 (aSec61).

were also detected in the endomembrane fractions (Figure $4 \mathrm{c}$, right). An absolute comparison with the plasma membrane fractions is not possible, because of differences in total protein, but a ratiometric comparison between treatments showed little difference in relative distributions. The band density ratios for GORK between plasma membrane fractions in 0.1 and $100 \mathrm{~mm} \mathrm{KCl}$ yielded values of 1.3 in the first experiment and 1.1 in the second. Thus, $\mathrm{KCl}$ treatments did not have a major effect on GORK distribution to the plasma membrane, indicating that vesicle traffic to and from the plasma membrane was unlikely to contribute appreciably to the changes observed in GORK-GFP distribution in vivo.

\section{GORK redistribution is fast and mirrors alkali cation- dependent channel gating}

We analysed the time-course of puncta dispersal, expressing GORK in tobacco epidermis which showed the same reversible formation of puncta and simplified manipulations. Transformed leaf sections were infiltrated with $0.1 \mathrm{~mm} \mathrm{KCl}$ and images collected before one half of the sections were re-infiltrated with $100 \mathrm{~mm} \mathrm{KCl}$. Samples were randomised and images were collected and analysed in blind assays following the second infiltration. The numbers of cells showing puntate distributions were assessed and then normalised to the measurements prior to the second infiltration. Figure 5 summarises these data with images collected before $(a, c)$ and after $(b, d)$ infiltration with $100 \mathrm{~mm} \mathrm{KCl}$, and shows a rapid decrease in the percentage of cells showing puncta, the count dropping to approximately $40 \%$ (Figure $5 \mathrm{e}$ ) within $10 \mathrm{~min}$ of treatments. Exponential fittings yielded a halftime of $2.4 \pm 0.5 \mathrm{~min}$ for the response. This analysis overestimates the halftime, as the experiments do not take into account the $\mathrm{K}^{+}$diffusion time across the cell wall which can slow diffusion by a factor of $10^{-2}$ to $10^{-4}$ (Canny, 1990). Assuming a $10^{-3}$-fold decrease, for $\mathrm{K}^{+}$the effect implies a diffusion coefficient of $6.10^{-9} \mathrm{~cm}^{2} \mathrm{sec}^{-1}$ and an increase in the root mean square time for bulk diffusion across the $2 \mu \mathrm{m}$ of cell wall to 100 $200 \mathrm{sec}$ (Hille, 2001), roughly equivalent to the time for GORK-GFP puncta dispersal. These values contrast with the dispersion of KAT1-GFP puncta during endocytosis (Sutter et al., 2007), which displayed a halftime of 10 $12 \mathrm{~min}$ and was complete only after $40-60 \mathrm{~min}$ following ABA treatments. The comparison supports our earlier observations indicating that the redistribution of GORKGFP is not associated with endocytosis.

The gating of GORK, and its homologs in Vicia and tobacco, responds over a similar time course to changes in alkali cation concentrations, including $\mathrm{Cs}^{+}$(Blatt, 1988; Armstrong et al., 1995; Blatt and Gradmann, 1997; Blatt et al., 1999; Bauly et al., 2000). We examined whether the distribution GORK in puncta was sensitive to the $\mathrm{K}^{+}$or to the $\mathrm{Cl}^{-}$concentration, and whether it showed ionic 

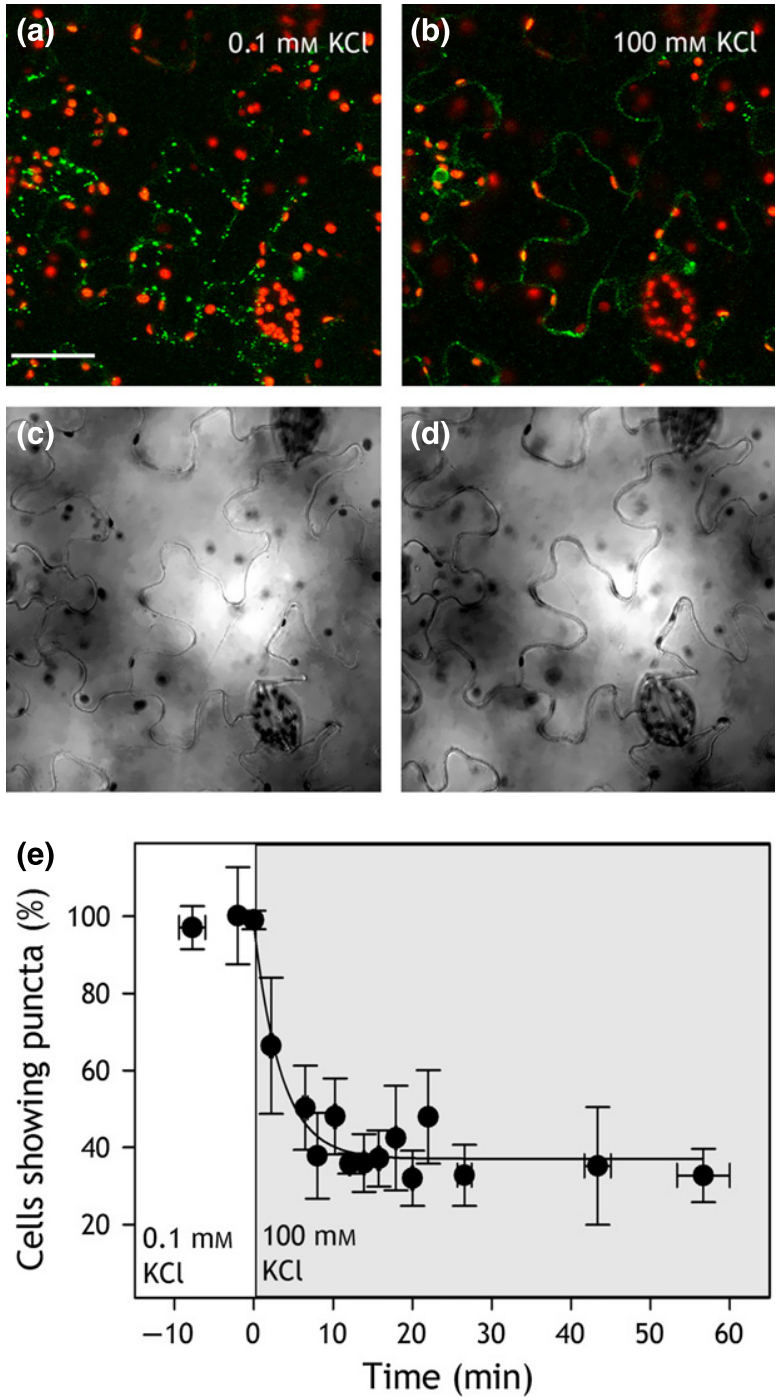

Figure 5. GORK-GFP puncta disperse rapidly on transfer to $100 \mathrm{~mm} \mathrm{KCl}$. (a-d) Confocal images (a, b) of GORK-GFP (green) and chloroplast fluorescence (red) expressed in tobacco epidermal cells with corresponding bright field (c, d) images collected in $0.1 \mathrm{~mm} \mathrm{KCl}(\mathrm{a}, \mathrm{c})$ and $30 \mathrm{~min}$ after transfer to $100 \mathrm{~mm} \mathrm{KCl}(\mathrm{b}, \mathrm{d})$ showing conversion from punctate to diffuse distribution of the channel. Scale bar, $50 \mu \mathrm{m}$.

(e) The percentage of transformed tobacco cells displaying GORK-GFP puncta as a function of time on transfer from 0.1 to $100 \mathrm{~mm} \mathrm{KCl}$ (grey). Data are means \pm SE of $n \geq 5$ independent experiments and were fitted by nonlinear least-squares to an exponential decay function of time (solid line).

sensitivities similar to those of gating. Experiments were carried out as before with pre-infiltrations of $0.1 \mathrm{~mm} \mathrm{KCl}$, but with either $100 \mathrm{~mm} \mathrm{KNO}_{3}$ or $50 \mathrm{~mm} \mathrm{MgCl}$ in the second infiltration. Leaf sections were examined for GORKGFP distribution after $20 \mathrm{~min}$. The results (Figure 6a) showed a similar decrease in punctate frequency to $45 \pm 10 \%$ in leaf sections treated with $100 \mathrm{~mm} \mathrm{KNO}_{3}$ but not with $50 \mathrm{~mm} \mathrm{MgCl}_{2}$. To avoid the 'digitizing' effect of counting cells, we also quantified GORK distribution by
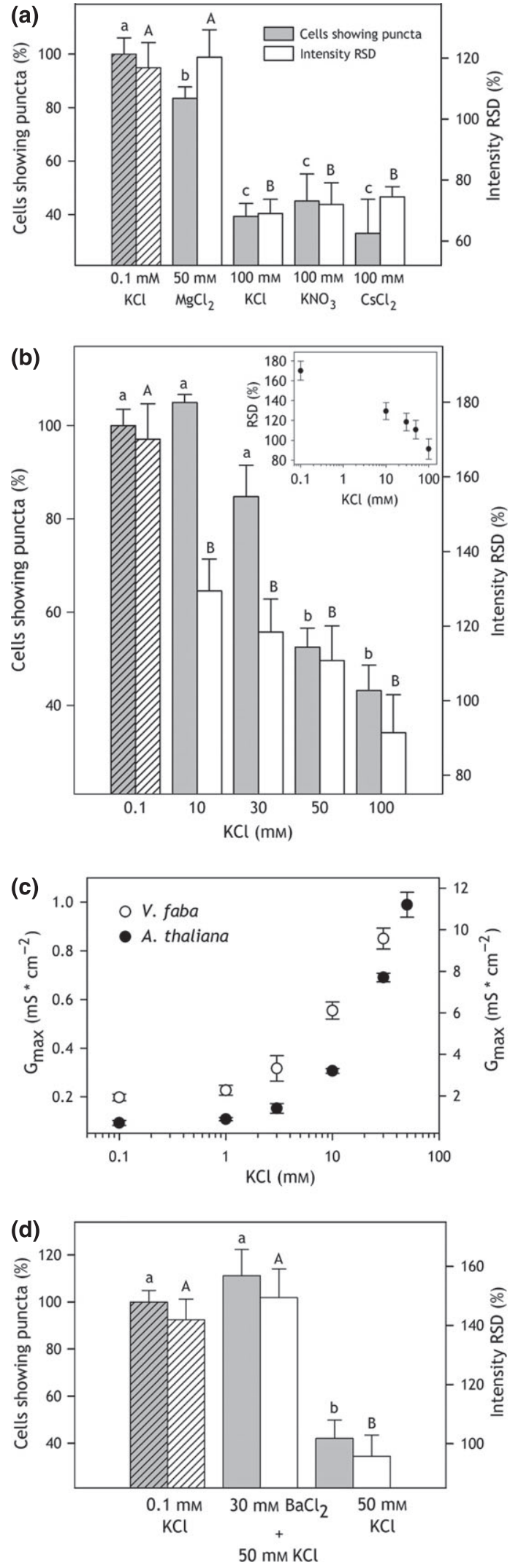

(C) 2014 The Authors The Plant Journal published by Society for Experimental Biology and John Wiley \& Sons Ltd. 
Figure 6. GORK-GFP dispersion is subject to $\mathrm{K}^{+}$, not $\mathrm{Cl}^{-}$, is equally sensitive to $\mathrm{K}^{+}$substitution with $\mathrm{Cs}^{+}$, and is suppressed by pretreatment with the channel blocker $\mathrm{Ba}^{2+}$.

(a) Quantification of GORK-GFP puncta in $0.1 \mathrm{~mm} \mathrm{KCl}$ (diagonal shading) and after treatment with $100 \mathrm{mM} \mathrm{KCl}, 100 \mathrm{mM} \mathrm{KNO}_{3}, 50 \mathrm{mM} \mathrm{MgCl}_{2}$ and $100 \mathrm{~mm} \mathrm{CsCl}$. Punctate distribution was analysed by two methods. The left ordinate and grey bars represent the percentage of cells showing puncta in any one image. The right ordinate and white bars represent the relative standard deviation (RSD) of intensities determined from a 1-pixel-wide line around the periphery of cells and normalized to the intensity means. Data are means \pm SE of $n>9$ independent experiments for each treatment.

(b) Percentage of cells showing GORK-GFP puncta (left ordinate, grey bars) and the intensity $\mathrm{SD}$ (right ordinate, white bars) in $0.1 \mathrm{~mm} \mathrm{KCl}$ (diagonal shading) and after treatment with $10,30,50$ and $100 \mathrm{~mm} \mathrm{KCl}$. Data are means \pm SE of $n>6$ independent for each treatment. Inset: Intensity RSD as a function of $[\mathrm{KCl}]$ outside plotted on a logarithmic scale.

(c) Maximum ensemble conductance of GORK in Arabidopsis guard cells (filled circles) and the homologous, outward-rectifying $\mathrm{K}^{+}$current in Vicia guard cells (open circles) as a function of $\left[\mathrm{K}^{+}\right]$outside. Data are derived and replotted as means \pm SE from prior publications [see (Blatt, 1988; Thiel and Blatt, 1991; Thiel et al., 1992; Blatt and Gradmann, 1997; Brearley et al., 1997; Blatt et al., 1999; Leyman et al., 1999; Sokolovski and Blatt, 2004; Chen et al., 2012; Wang et al., 2012)].

(d) Percentage of cells showing GORK-GFP puncta (left ordinate, grey bars) and the normalized relative standard deviation in intensity (RSD; right ordinate, white bars) in $0.1 \mathrm{~mm} \mathrm{KCl}$ (diagonal shading), after 30 min pretreatment with $30 \mathrm{~mm}$ of the $\mathrm{K}^{+}$channel blocker $\mathrm{BaCl}_{2}$, and after addition of $50 \mathrm{mM} \mathrm{KCl}$ to the $30 \mathrm{~mm} \mathrm{BaCl}_{2}$-treated samples. Data are means $\pm \mathrm{SE}$ of $n=5$ independent experiments. Significance at $P<0.05$ was analysed by ANOVA and pair-wise multiple comparison and are indicated in each case by lettering for the percentage of cells showing puncta (small letters) and RSD (capital letters).

analysis of the relative standard deviations (RSD) in fluorescence intensity around the periphery of the cells. This approach yielded the same pattern in $\mathrm{K}^{+}$dependence. As a further test, we also replaced the $\mathrm{KCl}$ solution with $100 \mathrm{~mm}$ $\mathrm{CsCl}$. Again, these substitutions gave a punctate distribution of $33 \pm 12 \%$ and a corresponding decrease in RSD, similar to that $100 \mathrm{~mm} \mathrm{KCl}$. We challenged leaf sections with different $\mathrm{K}^{+}$concentrations for comparison with GORK channel gating. Leaf disks were pretreated as before, then split for blind image acquisition and the section fragments re-infiltrated with $0.1,10,30,50$ and $100 \mathrm{~mm} \mathrm{KCl}$. The results (Figure $6 \mathrm{~b}$ ) showed that the percentage of cells with puncta decreased progressively with increasing $\mathrm{KCl}$ concentrations above $10 \mathrm{~mm}$, although a statistical analysis belies the trend. This pattern is similar to that of the ensemble conductance maximum $\left(G_{\max }\right)$ observed for the outward-rectifying $\mathrm{K}^{+}$channels in both Vicia and Arabidopsis guard cells (Figure 6c). Quantified by RSD, the effect of $\mathrm{KCl}$ concentration is evident across the entire concentration range. Finally, we tested whether the $\mathrm{K}^{+}$channel blocker $\mathrm{Ba}^{2+}$ (Armstrong and Taylor, 1980; Roelfsema and Prins, 1997; Romano et al., 1998; Hamilton et al., 2000) might affect the distribution of GORK-GFP. In this case, leaf disks were pretreated with $0.1 \mathrm{~mm} \mathrm{KCl}$ and split as before, one half of each disk then re-infiltrated either with $50 \mathrm{~mm}$ $\mathrm{KCl}$ or first with $30 \mathrm{~mm} \mathrm{BaCl}$ and, after 30 min, with $30 \mathrm{~mm}$ $\mathrm{BaCl}_{2}$ plus $50 \mathrm{~mm} \mathrm{KCl}$. Figure $6 \mathrm{c}$ shows that infiltrating with
$\mathrm{BaCl}_{2}$ was sufficient to prevent the dispersal of the GORK puncta. These findings indicate a close association between GORK gating and the distribution of GORK-GFP in puncta and we return to the observations below.

\section{DISCUSSION}

Only recently has attention in channel regulation turned to the traffic of ion channel proteins and to changes in the population of ion channels active at the plasma membrane. Notable among the few studies in plants is the ABA-evoked endocytosis of the KAT1 $\mathrm{K}^{+}$channel, its slower recycling to the plasma membrane (Sutter et al., 2007), and a role for the vesicle-trafficking protein SYP121 in recovery from programmed closure of guard cells (Eisenach et al., 2012). Until now, no information has been forthcoming relating to the traffic of GORK, the major outward-rectifying $\mathrm{K}^{+}$channel that facilitates $\mathrm{K}^{+}$efflux during stomatal closure in Arabidopsis, although changes in ensemble channel conductance and the voltage-dependence of gating are known for these and homologous outward-rectifying channels (Blatt, 1990, 1992; Thiel et al., 1992). We anticipated these effects on GORK current might result from channel traffic, but the studies outlined above contradict this expectation. Here we report that the GORK $\mathrm{K}^{+}$channel, like KAT1, appears in discrete puncta at the guard cell periphery. These clusters form independently of the structures assembled by KAT1 (Meckel et al., 2004; Sutter et al., 2006, 2007) and are not affected by ABA, but form and disperse reversibly with external $\mathrm{K}^{+}$concentration. Three additional lines of evidence associate GORK puncta and their dispersal with short-term changes in channel gating and conductance, rather than with channel traffic. (i) The mobility of GORK-GFP was unaffected by ABA, nor was it altered between the punctate and dispersed forms of the channel. (ii) Two-phase partitioning experiments yielded no substantial difference in membrane distribution between punctate and dispersed forms of the channel, unlike KAT1 (Sutter et al., 2007; Eisenach et al., 2012). (iii) Dispersal of the GORK puncta was rapid and demonstrably sensitive to extracellular cations, parallelling gating and block in these channels. We suggest that conformational changes of the channel and its gate with $\mathrm{K}^{+}$are connected structurally to the clustering of GORK within the plane of the plasma membrane. Such clustering may signal changes in the external ionic environment, possibly by exploiting the changing capacity of GORK, when in puncta, to interact with other cytoplasmic or plasma membrane proteins.

\section{GORK puncta are distinct from the trafficking platforms of the KAT1 channel}

Clustering of the GORK $\mathrm{K}^{+}$channels within puncta at the surface of tobacco epidermal cells and Arabidopsis guard cells complements studies of the other major $\mathrm{K}^{+}$channel 
subgroup, represented by KAT1 (Meckel et al., 2004; Sutter et al., 2006, 2007; Homann et al., 2007), and supports electrophysiological evidence that many functional $\mathrm{K}^{+}$channels in plants are distributed non-homogenously over the plasma membrane surface (Tester, 1990; Hille, 2001). The puncta formed by GORK are similar in size to those of KAT1, but are physically distinct as evident from co-localisation studies (Figures 1, S3 and S4). GORK puncta also differ from those of KAT1 in their mobility and sensitivity to external stimuli. Whereas the puncta of KAT1 are lost in ABA (Sutter et al., 2007) and reform in a manner sensitive to the vesicle-trafficking protein SYP121 (Eisenach et al., 2012), we found GORK to be insensitive to $A B A$ and SYP121 but dependent on the extracellular $\mathrm{K}^{+}$concentration (Figures 2, 5 and 6). These findings alone distinguish the structural characteristics of the two $\mathrm{K}^{+}$channels.

Physical clustering of channel and other proteins is well known also in animal cells (Lai and Jan, 2006; O'Connell et al., 2010; Zilly et al., 2011; Pristera et al., 2012) and, in neurons, often demarcates platforms for vesicle fusion and channel traffic (Lai and Jan, 2006; Deutsch et al., 2012). Much the same conclusion was reached for the puncta formed of the KAT1 channel when expressed in tobacco (Sutter et al., 2006, 2007): Our analysis of GORK-GFP recovery after photobleaching suggested that roughly $10 \%$ may be mobile within the cell (Figure 3), possibly through vesicle traffic. However, two-phase partitioning failed to uncover a substantial change in GORK distribution between plasma- and endomembranes fractions, even following transfer to $100 \mathrm{~mm} \mathrm{KCl}$ to evoke a dispersal of the puncta. GORK puncta also dissociated reversibly in the syp121 mutant that is defective in KAT1 trafficking to the plasma membrane (Eisenach et al., 2012). We cannot discount a role for vesicle traffic in the mobility of GORK, but these results indicate that any such contribution to GORK clustering and dispersal is small and of a magnitude that might only be resolved by fluorescence analysis in vivo over extended time periods (Luu et al., 2012).

We stress that plant ion channels, including GORK, normally express at levels that are too low for detection by confocal microscopy. We used GORK-GFP constructs driven by the Ubiquitin-10 promoter, $P U B 010$, that drives expression at lower levels that the 35S CaMV promoter (Grefen et al., 2010b), and we confirmed channel function of GORK-GFP. We cannot rule out that pUBQ10-driven expression misrepresents GORK distribution. Nonetheless, GORK-GFP generally was not observed to accumulate in the endoplasmic reticulum, and GORK puncta dissociated reversibly in vivo. These findings support the idea that clustering of the $\mathrm{K}^{+}$channels is physiologically relevant. Clustering of membrane proteins in lipid rafts is common and often accompanied by restricted lateral diffusion (Bhat et al., 2005; Lai and Jan, 2006; Mongrand et al., 2010). Such rafts have been implicated in signal transduction, polarised secretion, membrane traffic and pathogen entry. Membrane rafts are generally acknowledged to form below the resolution limit of the light microscope and, thus, are 5- to 10-fold smaller than the GORK-GFP clusters we observed. However, such small-scale rafts may aggregate in response to external stimuli (Bhat et al., 2005; Mongrand et al., 2010), potentially underpinning the larger clusters observed with the GORK $\mathrm{K}^{+}$channel. Our FRAP analysis (Figure 3) showed that cluster dispersion was not associated with a significant increase in mobility or altered macroscopic diffusion. Thus, it may be that GORK remains anchored with other proteins in raft-like microdomains, even in high external $\mathrm{K}^{+}$.

\section{A physiological role for GORK clustering associated with $\mathrm{K}^{+}$-dependent gating?}

The most striking aspects of the physical organisation of GORK are its parallels to the $\mathrm{K}^{+}$-sensitivity of gating and ensemble conductance. The activities of the Kv-like channels GORK and SKOR in Arabidopsis, as well as outwardrectifying $\mathrm{K}^{+}$channels in other plants, show a characteristic dependence on external alkali cation concentration as well as voltage (Blatt, 1988; Armstrong et al., 1995; Blatt and Gradmann, 1997; Blatt et al., 1999; Ache et al., 2000; Bauly et al., 2000; Johansson et al., 2006). These characteristics include a displacement in channel conductance in parallel with the equlibrium voltage for $\mathrm{K}^{+}$(see Figure S1), an increase in the ensemble conductance maximum, and the ability of $\mathrm{Cs}^{+}$to substitute for $\mathrm{K}^{+}$outside. Channel gating responds in a near-instantaneous manner to $\mathrm{K}^{+}$within the timescale of bulk solution changes, and changes in ensemble conductance are only marginally slower (Blatt, 1988; Blatt and Gradmann, 1997). Johansson et al. (2006) have shown that external cations affect the $\mathrm{K}^{+}$channel through interactions of the pore loop and pore-lining $\alpha$-helices that, in turn, are likely to influence the conformational states of the outer ring of polypeptides formed by the voltage-sensor domains of the channels (Dreyer and Blatt, 2009): in effect, occupancy of the inner vestibule of the pore at high $\mathrm{K}^{+}$concentrations appears to favour a temporally-stable, 'locked-closed' state. We speculate that these conformations may affect the local packing of the $\mathrm{K}^{+}$channel proteins within the plasma membrane, which becomes evident at a macroscopic level as cluster dissolution. Barium suppression of the GORK puncta dispersal (Figure 6), and the parallels in timecourse for cluster dissolution and gating in $100 \mathrm{~mm} \mathrm{~K}^{+}$, makes this hypothesis especially compelling. Barium enters the pores of many $\mathrm{K}^{+}$ channels (Vergani et al., 1997; Hamilton et al., 2000; Jiang and MacKinnon, 2000; Hille, 2001), including GORK (Roelfsema and Prins, 1997; Ache et al., 2000), and is thought to block by occluding the selectivity filter (Jiang and MacKinnon, 2000; Rowley and Roux, 2013). It follows that, with $\mathrm{Ba}^{2+}$ present, the channel is likely to become trapped in the 
'locked-closed' state with $\mathrm{K}^{+}$in the inner vestibule of the channel, isolated from the pool of $\mathrm{K}^{+}$in the cytosol and, of course, from changes in $\mathrm{K}^{+}$concentration outside. Thus, the effect on GORK cluster dispersal implies a close connection to channel conformation in gating and to channel conductance.

What role might reversible clustering of the $\mathrm{K}^{+}$channels serve? In addition to the voltage-dependence of the channel gate, at least two physiological phenomena may be connected to this behaviour. First, we suggest that clustering may serve to control the pool of GORK channels active in the plasma membrane by sequestering channels, possibly in a non-activatable state. Such behaviour might be seen to withdraw channels from the active pool at the membrane much as an iceberg constrains a volume of water within a crystalline array, preventing its movement and ability to act as a general solvent. For the channels at low external $\mathrm{K}^{+}$concentrations, the effect of such an 'iceberg' model might be seen to confer a synergy to the voltage-dependence of the channels as the $\mathrm{K}^{+}$concentration decreases while reducing the maximum $\mathrm{K}^{+}$flux capacity of the channel population (Blatt, 1988, 1990, 1992; Thiel et al., 1992; Armstrong et al., 1995; Blatt et al., 1999; Bauly et al., 2000) (see also Figure 6). Similar concepts have been proposed to explain the clustering of mammalian $\mathrm{K}^{+}$channels (Misonou and Trimmer, 2004), although correlating channel clustering and ensemble conductance has proven difficult (O'Connell et al., 2010).

We can propose a second role for GORK clustering that builds on this iceberg analogy. $\mathrm{K}^{+}$flux across the plasma membrane is known to be tightly linked to membrane surface area and volume control (Zonia and Munnik, 2007). Work from this laboratory has uncovered the wide-spread interaction between subsets of vesicle-trafficking (SNARE) proteins and $\mathrm{K}^{+}$channels that have profound effects on channel gating and net $\mathrm{K}^{+}$uptake (Honsbein et al., 2009, 2011; Grefen et al., 2010a). These interactions are implicated in priming the SNAREs to catalyse membrane fusion (Karnik et al., 2013). It is plausible, therefore, that the cell might exploit the $\mathrm{K}^{+}$-sensitivity of GORK clustering to regulate vesicle traffic of other membrane components, adjusting the rate of cell surface expansion with $\mathrm{K}^{+}$uptake and cell volume. For example, $\mathrm{K}^{+}$accumulation is enhanced in guard cells at high external $\mathrm{K}^{+}$, which also promotes the dissolution of GORK clusters. We can imagine that 'freeing' the channels from within the clusters facilitates SNARE and other interactions to accelerate vesicle traffic for the increase in cell volume.

In conclusion, we have uncovered a new and unusual process that may help to understand how the $\mathrm{K}^{+}$channels of Arabidopsis guard cells, and other plant cells, sense and respond to external $\mathrm{K}^{+}$concentration. To date, the phenomenon of $\mathrm{K}^{+}$-dependent channel clustering in plants appears unique to the outward-rectifying $\mathrm{K}^{+}$channel
GORK, but we anticipate that similar characteristics will be forthcoming for other outward-rectifying $\mathrm{K}^{+}$channels in plants. For GORK, the properties of channel clustering shows many hallmarks of $\mathrm{K}^{+}$-dependent gating and conductance, implicating a close connection that is now open to testing, for example through a combination of protein domain exchange with a non-clustering channel such as AKT1 (Honsbein et al., 2009). We suspect that the organisation of GORK and other channels in this manner is likely to contribute both as a mechanism regulating the channels and as a platform for sensing and responding to environmental cues.

\section{MATERIAL AND METHODS}

\section{Molecular cloning}

The GORK coding sequence was amplified from rosetteleaf cDNA using the oligonucleotide primers $5^{\prime}$-attB1 TA ATG GGA CGT CTC CGG-3' and 5'-attB2 G TGT TTG ATC AGT AGT ATC ACT G-3', recombined into Gateway ${ }^{\text {TM }}$ entry vector pDONR207 with BP clonase II (Life Technologies, http://www.lifetechnologies.com), and transformed into the E. coli strain CopyCutter EPI400 (Cambio, http://www.cam bio.co.uk) (Grefen et al., 2009). Clones were verified by sequencing (GATC, http://www.gatc-biotech.com/) and recombined into expression vectors via LR-reaction (Life Technologies). The $p U B Q 10$ vector system was used to generate GORK constructs C-terminally tagged with GFP and RFP (Grefen et al., 2010b). Constructs were transformed into Agrobacterium tumefaciens (strain GV3101) and were verified by rescue in $E$. coli and restriction digest analysis. A single $A$. tumefaciens clone was used for transient transformation of tobacco and stable transformation of Arabidopsis.

The coding sequence for GORK-GFP was amplified from the $p U B Q 10-D E S T$ expression construct for re-cloning into the oocyte expression vector pGT-DEST (Grefen et al., 2010b) using the oligonucleotide primers $5^{\prime}$-A GTT AAC ATG GGA CGT CTC CGG AGA C-3' and 5'-C AGG CCT TTA TAA CTT GTA CAG CTC GTC CAT GC-3'. These primers incorporated $5^{\prime} \mathrm{Hpal}$ and Stul overhangs, respectively. Blunt-end restriction of the oocyte expression vector $p G T$ DEST with $\mathrm{Mscl}$ and of the PCR product with $\mathrm{Hpal}$ and Stul was followed by ligation using T4 DNA Ligase (Promega, http://www.promega.com/) before verification by sequencing.

\section{Electrophysiology}

GORK-GFP was expressed in Xenopus oocytes using $p G T$ GORK-GFP plasmid DNA (Vergani et al., 1998; Grefen et al., 2010a), and currents were recorded by two-electrode voltage clamp as described previously (Johansson and Blatt, 2006). Measurements were carried out using 
microelectrodes filled with $3 \mathrm{M} \mathrm{K}^{+}$-acetate and with oocytes bathed in $10 \mathrm{~mm}$ HEPES-NaOH, pH 7.2, with $1.8 \mathrm{~mm} \mathrm{MgCl}$, $1.8 \mathrm{~mm} \mathrm{CaCl}_{2}$ and additions of $10 \mathrm{~mm}, 30 \mathrm{~mm}$ or $96 \mathrm{~mm} \mathrm{KCl}$ balanced by $\mathrm{NaCl}$ to give a total salt concentration of $100 \mathrm{~mm}$.

\section{Plant growth, transformation and microscopy}

Arabidopsis thaliana Col0, syp121 and gork [SALK_082258C (Alonso et al., 2003)] mutant plants were grown and transformed by floral dip (Clough and Bent, 1998) and $T_{1}$ transformants were selected for BASTA ${ }^{\circledR}$ resistance (1:1000 dilution; Bayer Cropscience, http:// www.cropscience.bayer.com). Seeds of the $T_{2}, T_{3}$ and $T_{4}$ generations were selected in the same manner. Leaves of Nicotiana tabacum (tobacco) were transformed by infiltration with Agrobacterium carrying the GORK-GFP construct (Geelen et al., 2002), and were analysed 72-120 h after transformation.

GORK-GFP fluorescence was resolved on a LSM510META confocal microscope (Zeiss, http://www.zeiss.com) using the 488-nm line of an Argon laser and fluorescence was collected as reflectance from a $545-\mathrm{nm}$ dichroic mirror after passage through a 505-530 nm interference filter. Chloroplast fluorescence was collected concurrently after passage through the 545-nm dichroic mirror and a long pass $560 \mathrm{~nm}$ emission filter. Fluorescence recovery after photobleaching (FRAP) was carried out after fluorophore bleaching with the 488 laser using a pixel time of $1.6 \mathrm{sec}$ (2.4 $\mathrm{mJ}$ exposure energy). Bleaching, detection and analysis settings were standardised between experiments for ROI dimensions, laser power, magnification and detection settings and fluorescence was corrected for decay during acquisition.

Imaging was carried out using young rosette leaves of Arabidopsis mounted in a custom-build perfusion chamber that enabled continuous perfusion and solution changes during experiments. Buffers included $0.003 \%$ Silwet L77 (Lehle Seeds, http://www.lehleseeds.com) to ensure cuticle penetration. For tobacco, imaging was carried out on $1-\mathrm{cm}$ diameter leaf discs after vacuum infiltration with treatment buffers before remounting. All buffers were based on $10 \mathrm{~mm}$ NaMES, pH6.1. The salts $\mathrm{KCl}, \mathrm{KNO}_{3}, \mathrm{CsCl}_{2}, \mathrm{MgCl}_{2}$ and $\mathrm{BaCl}_{2}$ were added as indicated and osmotic strength was adjusted using mannitol. Abscisic acid (ABA) was prepared as before (Blatt and Armstrong, 1993) and diluted in buffer to $40 \mu \mathrm{M}$ for use. For ABA treatments, leaves were infiltrated and incubated in $5 \mathrm{~mm} \mathrm{Ca}^{2+}$-MES, pH 6.1, $10 \mathrm{~mm}$ $\mathrm{KCl}$ for $2 \mathrm{~h}$ under $100 \mu \mathrm{mol} \mathrm{m}{ }^{-2} \mathrm{sec}^{-1}$ white light. Images were collected, the leaves reinfiltrated using the same buffer with the addition of $A B A$, and the leaves re-imaged after 30 and $60 \mathrm{~min}$. Tobacco disc analysis was carried out in blind assays. GORK puncta were quantified both as the percentage of cells showing puncta and by relative standard deviation (RSD) after normalizing to the intensity means.

\section{Protein biochemistry}

GORK distribution between plasma membrane and endomembrane fractions was determined by aqueous twophase partitioning. Arabidopsis leaf tissues were infiltrated in either $100 \mathrm{~mm} \mathrm{KCl}$ or $0.1 \mathrm{~mm} \mathrm{KCl}$ buffers and incubated for $2 \mathrm{~h}$. All subsequent steps were carried out at $4^{\circ} \mathrm{C}$ as described before (Honsbein et al., 2009). Proteins were separated by electrophoresis and transferred onto PVDF membranes (Honsbein et al., 2009; Karnik et al., 2013) and were probed overnight with primary antibody, either aGORK [1:100]; aAHA [1:5000, (Villalba et al., 1991)], $\alpha \operatorname{Sec} 61$ [1:3000, (Yuasa et al., 2005)], or aGFP [1:200; Abcam, http://www.abcam.co.uk]. Horseradish peroxidasecoupled, $\alpha$-rabbit IgG secondary antibody (1:100 000) was used for detection with WestFemto SuperSignal (Pierce; Thermo Scientific, http://www.thermofischer.com). In some experiments, membranes were re-probed after stripping by incubation in $100 \mathrm{~mm} \beta$-Mercaptoethanol, 2\% SDS, $62.5 \mathrm{~mm}$ Tris- $\mathrm{HCl}, \mathrm{pH} 6.7$ at $70^{\circ} \mathrm{C}$ for $45 \mathrm{~min}$.

\section{Data analysis}

Statistical analyses were carried out using SIGMAPLOT 11 (Systat Software, Inc., http://www.sigmaplot.com). Non-linear least-squares fittings used a Marquardt-Levenberg algorithm (Marquardt, 1963). Significance was tested using Student's $t$-test and analysis of variance (ANOVA). Otherwise, data are reported as means \pm SE of $n$ observations.

\section{Chemicals and media}

All chemicals were from Sigma (http://www.sigma-aldrich. com) unless otherwise noted.

\section{ACKNOWLEDGEMENTS}

We thank Christopher Grefen and Annegret Honsbein for support in molecular cloning and electrophysiology, respectively, and Amparo Ruiz-Prado for plant maintenance. This work was supported by a postgraduate grant-in-aid from Plant Bioscience Ltd. (CE), by BBSRC grants BB/H009817/1 and BB/I024496/1 (MRB), and by a Begonia Trust scholarship (MP).

\section{SUPPORTING INFORMATION}

Additional Supporting Information may be found in the online version of this article.

Figure S1. The GFP-tagged GORK construct encodes a functional $\mathrm{K}^{+}$channel.

Figure S2. GORK current is blocked by the $\mathrm{K}^{+}$channel antagonist tetraethylammonium chloride $\left(\mathrm{TEA}^{+}\right)$.

Figure S3. The $\mathrm{K}^{+}$channels GORK and KAT1 assemble in physically-distinct puncta.

Figure S4. KAT1-GFP and GORK-RFP show intermediate degree of overlap, suggesting that the two channel proteins do not coreside in the same punctate structures at the plasma membrane.

Figure S5. GORK-GFP clusters appear in strands of plasma membrane on cell plasmolysis.

Figure S6. GORK-GFP clusters are unaffected by ABA. 
Figure S7. Relative standard distribution (RSD) of GORK-GFP at the guard cell periphery is unaffected by ABA.

Figure S8. GORK peptide antigen design.

\section{REFERENCES}

Ache, P., Becker, D., Ivashikina, N., Dietrich, P., Roelfsema, M.R.G. and Hedrich, R. (2000) GORK, a delayed outward rectifier expressed in guard cells of Arabidopsis thaliana, is a $\mathrm{K}^{+}$-selective, $\mathrm{K}^{+}$-sensing ion channel. FEBS Lett. 486, 93-98.

Alonso, J.M., Stepanova, A.N., Leisse, T.J. et al. (2003) Genome-wide insertional mutagenesis of Arabidopsis thaliana. Science, 301, 653-657.

Armstrong, C.M. and Taylor, S.R. (1980) Interaction of barium ions with potassium channels in squid giant axons. Biophys. J. 30, 473-488.

Armstrong, F., Leung, J., Grabov, A., Brearley, J., Giraudat, J. and Blatt, M.R. (1995) Sensitivity to abscisic acid of guard cell $\mathrm{K}^{+}$channels is suppressed by abi1-1, a mutant Arabidopsis gene encoding a putative protein phosphatase. Proc. Natl Acad. Sci. USA, 92, 9520-9524.

Bauly, J.M., Sealy, I.M., MacDonald, H. et al. (2000) Overexpression of auxin-binding protein enhances the sensitivity of guard cells to auxin Plant Physiol. 124, 1229-1238.

Bhat, R.A., Miklis, M., Schmelzer, E., Schulze-Lefert, P. and Panstruga, R. (2005) Recruitment and interaction dynamics of plant penetration resistance components in a plasma membrane microdomain. Proc. Natl Acad. Sci. USA, 102, 3135-3140.

Blatt, M.R. (1988) Potassium-dependent bipolar gating of potassium channels in guard cells. J. Membr. Biol. 102, 235-246.

Blatt, M.R. (1990) Potassium channel currents in intact stomatal guard cells: rapid enhancement by abscisic acid. Planta, 180, 445-455.

Blatt, M.R. (1992) K ${ }^{+}$channels of stomatal guard cells: characteristics of the inward rectifier and its control by pH. J. Gen. Physiol. 99, 615-644.

Blatt, M.R. (2000) Cellular signaling and volume control in stomatal movements in plants. Annu. Rev. Cell Dev. Biol. 16, 221-241.

Blatt, M.R. and Armstrong, F. (1993) $\mathrm{K}^{+}$channels of stomatal guard cells: abscisic acid-evoked control of the outward rectifier mediated by cytoplasmic pH. Planta, 191, 330-341.

Blatt, M.R. and Grabov, A. (1999) $\mathrm{H}^{+}$-mediated control of ion channels in guard cells of higher plants. In $\mathrm{pH}$ in Biological Systems (Egginton, S., Taylor, E.W. and Raven, J.A., eds). Cambridge: Cambridge University Press, pp. 155-176.

Blatt, M.R. and Gradmann, D. (1997) $\mathrm{K}^{+}$-sensitive gating of the $\mathrm{K}^{+}$outward rectifier in Vicia guard cells. J. Membr. Biol. 158, 241-256.

Blatt, M.R. and Thiel, G. (1993) Hormonal control of ion channel gating. Annu. Rev. Plant Physiol. Mol. Biol. 44, 543-567.

Blatt, M.R. and Thiel, G. (1994) $\mathrm{K}^{+}$channels of stomatal guard cells: bimodal control of the $\mathrm{K}^{+}$inward-rectifier evoked by auxin. Plant J. 5, 55-68.

Blatt, M.R., Thiel, G. and Trentham, D.R. (1990) Reversible inactivation of K ${ }^{+}$ channels of Vicia stomatal guard cells following the photolysis of caged inositol 1,4,5- trisphosphate. Nature, 346, 766-769.

Blatt, M.R., Grabov, A., Brearley, J., HammondKosack, K. and Jones, J.D.G. (1999) $\mathrm{K}^{+}$channels of $\mathrm{Cf}-9$ transgenic tobacco guard cells as targets for Cladosporium fulvum Avr9 elicitor-dependent signal transduction. Plant J. 19, 453-462.

Blatt, M.R., Garcia-Mata, C. and Sokolovski, S. (2007) Membrane transport and $\mathrm{Ca}^{2+}$ oscillations in guard cells. In Rhythms in Plants (Mancuso, $\mathrm{S}$. and Shabala, S., eds). Berlin: Springer, pp. 115-134.

Brearley, J., Venis, M.A. and Blatt, M.R. (1997) The effect of elevated $\mathrm{CO}_{2}$ concentrations on $\mathrm{K}^{+}$and anion channels of Vicia faba L. guard cells. Planta, 203, 145-154.

Canny, M.J. (1990) Rates of diffusion in wheat leaves. New Phytol. 116, 263 268.

Chen, Z.H., Eisenach, C., Xu, X.O., Hills, A. and Blatt, M.R. (2012) Protocol: optimised electrophyiological analysis of intact guard cells from Arabidopsis. Plant Methods, 8, 15-25.

Clough, S.J. and Bent, A.F. (1998) Floral dip: a simplified method for Agrobacterium-mediated transformation of Arabidopsis thaliana. Plant J. 16, 735-743.

Deutsch, E., Weigel, A.V., Akin, E.J., Fox, P., Hansen, G., Haberkorn, C.J., Loftus, R., Krapf, D. and Tamkun, M.M. (2012) Kv2.1 cell surface clusters are insertion platforms for ion channel delivery to the plasma membrane. Mol. Biol. Cell, 23, 2917-2929.

Dreyer, I. and Blatt, M.R. (2009) What makes a gate? The ins and outs of Kv-like $\mathrm{K}^{+}$channels in plants. Trends Plant Sci. 14, 383-390.

Eisenach, C., Chen, Z.H., Grefen, C. and Blatt, M.R. (2012) The trafficking protein SYP121 of Arabidopsis connects programmed stomatal closure and $\mathrm{K}^{+}$channel acivity with vegetative growth. Plant J. 69, 241-251.

Geelen, D., Leyman, B., Batoko, H., Di Sansabastiano, G.P., Moore, I. and Blatt, M.R. (2002) The abscisic acid-related SNARE homolog NtSyr1 contributes to secretion and growth: evidence from competition with its cytosolic domain. Plant Cell, 14, 387-406.

Grabov, A. and Blatt, M.R. (1998) Membrane voltage initiates $\mathrm{Ca}^{2+}$ waves and potentiates $\mathrm{Ca}^{2+}$ increases with abscisic acid in stomatal guard cells. Proc. Natl Acad. Sci. USA, 95, 4778-4783.

Grefen, C., Obrdlik, P. and Harter, K. (2009) The determination of protein-protein interactions byt the mating-based split-ubiquitin system (mbSUS). Methods Mol. Biol. 479, 1-17.

Grefen, C., Chen, Z.H., Honsbein, A., Donald, N., Hills, A. and Blatt, M.R (2010a) A novel motif essential for SNARE interaction with the $\mathrm{K}^{+}$channel KC1 and channel gating in Arabidopsis. Plant Cell, 22, 3076-3092.

Grefen, C., Donald, N., Hashimoto, K., Kudla, J., Schumacher, K. and Blatt M.R. (2010b) A ubiquitin-10 promoter-based vector set for fluorescent protein tagging facilitates temporal stability and native protein distribution in transient and stable expression studies. Plant J. 64, 355-365.

Hamilton, D.W.A., Hills, A., Kohler, B. and Blatt, M.R. (2000) $\mathrm{Ca}^{2+}$ channels at the plasma membrane of stomatal guard cells are activated by hyperpolarization and abscisic acid. Proc. Natl Acad. Sci. USA, 97, 4967-4972.

Hedrich, R., Neimanis, S., Savchenko, G., Felle, H.H., Kaiser, W.M. and Heber, U. (2001) Changes in apoplastic pH and membrane potential in leaves in relation to stomatal responses to $\mathrm{CO}_{2}$, malate abscisic acid or interruption of water supply. Planta, 213, 594-601.

Hille, B. (2001) Ionic Channels of Excitable Membranes. Sunderland, MA: Sinauer Press.

Homann, U., Meckel, T., Hewing, J., Hutt, M.T. and Hurst, A.C. (2007) Distinct fluorescent pattern of KAT1: GFP in the plasma membrane of Vicia faba guard cells. Eur. J. Cell Biol. 86, 489-500.

Honsbein, A., Sokolovski, S., Grefen, C., Campanoni, P., Pratelli, R., Paneque, M., Chen, Z.H., Johansson, I. and Blatt, M.R. (2009) A tripartite SNARE- $\mathrm{K}^{+}$channel complex mediates in channel-dependent $\mathrm{K}^{+}$nutrition in Arabidopsis. Plant Cell, 21, 2859-2877.

Honsbein, A., Blatt, M.R. and Grefen, C. (2011) A molecular framework for coupling cellular volume and osmotic solute transport control. J. Exp. Bot. 62, 2363-2370.

Hosy, E., Vavasseur, A., Mouline, K. et al. (2003) The Arabidopsis outward $\mathrm{K}^{+}$channel GORK is involved in regulation of stomatal movements and plant transpiration. Proc. Natl Acad. Sci. USA, 100, 5549-5554.

Hurst, A.C., Meckel, T., Tayefeh, S., Thiel, G. and Homann, U. (2004) Trafficking of the plant potassium inward rectifier KAT1 in guard cell protoplasts of Vicia faba. Plant J. 37, 391-397.

Jiang, Y.X. and MacKinnon, R. (2000) The barium site in a potassium chan nel by X-ray crystallography. J. Gen. Physiol. 115, 269-272.

Johansson, I. and Blatt, M.R. (2006) Interactive domains between pore loops of the yeast $\mathrm{K}^{+}$channel TOK1 associate with extracellular $\mathrm{K}^{+}$sensitivity. Biochem. J. 393, 645-655.

Johansson, I., Wulfetange, K., Poree, F. et al. (2006) External $\mathrm{K}^{+}$modulates the activity of the Arabidopsis potassium channel SKOR via an unusual mechanism. Plant J. 46, 269-281.

Karnik, R., Grefen, C., Bayne, R., Honsbein, A., Koehler, T., Kioumourtzog lou, D., Williams, M., Bryant, N.J. and Blatt, M.R. (2013) Arabidopsis Sec1/Munc18 protein SEC11 is a competitive and dynamic modulator of SNARE binding and SYP121-dependent vesicle traffic. Plant Cell, 25, 1368-1382.

Kim, T.H., Bohmer, M., Hu, H.H., Nishimura, N. and Schroeder, J.I. (2010 Guard cell signal transduction network: advances in understanding abscisic acid, $\mathrm{CO}_{2}$, and $\mathrm{Ca}^{2+}$ signaling. Annu. Rev. Plant Biol. 61, 561-591.

Lai, H.C. and Jan, L.Y. (2006) The distribution and targeting of neuronal voltage-gated ion channels. Nat. Rev. Neurosci. 7, 548-562.

Lebaudy, A., Very, A.A. and Sentenac, H. (2007) K+ channel activity in plants: genes, regulations and functions. FEBS Lett. 581, 2357-2366. 
Leyman, B., Geelen, D., Quintero, F.J. and Blatt, M.R. (1999) A tobacco syntaxin with a role in hormonal control of guard cell ion channels. Science 283, 537-540.

Luu, D.T., Martiniere, A., Sorieul, M., Runions, J. and Maurel, C. (2012) Fluorescence recovery after photobleaching reveals high cycling dynamics of plasma membrane aquaporins in Arabidopsis roots under salt stress. Plant J. 69, 894-905.

Marquardt, D. (1963) An algorithm for least-squares estimation of nonlinear parameters. J. Soc. Ind. Appl. Math. 11, 431-441.

Meckel, T., Hurst, A.C., Thiel, G. and Homann, U. (2004) Endocytosis against high turgor: intact guard cells of Vicia faba constitutively endocytose fluorescently labelled plasma membrane and GFP-tagged $\mathrm{K}^{+}$-channel KAT1. Plant J. 39, 182-193.

Meckel, T., Hurst, A.C., Thiel, G. and Homann, U. (2005) Guard cells undergo constitutive and pressure-driven membrane turnover. Protoplasma, 226, 23-29.

Misonou, H. and Trimmer, J.S. (2004) Determinants of voltage-gated potassium channel surface expression and localization in mammalian neu rons. Crit. Rev. Biochem. Mol. Biol. 39, 125-145.

Mongrand, S., Stanislas, T., Bayer, E.M.F., Lherminier, J. and Simon-Plas, F. (2010) Membrane rafts in plant cells. Trends Plant Sci. 15, 656-663.

O'Connell, K.M.S., Loftus, R. and Tamkun, M.M. (2010) Localization-dependent activity of the Kv2.1 delayed-rectifier K+ channel. Proc. Natl Acad. Sci. USA, 107, 12351-12356.

Pardo, J.M. and Serrano, R. (1989) Structure of a plasma membrane $\mathrm{H}^{+}$-ATPase gene from the plant Arabidopsis thaliana. J. Biol. Chem. 264, 85578562.

Pristera, A., Baker, M.D. and Okuse, K. (2012) Association between tetrodotoxin resistant channels and lipid rafts regulates sensory neuron excitability. PLoS One, 7, e40078.

Roelfsema, M.R. and Hedrich, R. (2010) Making sense out of $\mathrm{Ca2}^{+}$signals: their role in regulating stomatal movements. Plant, Cell Environ. 33, 305321.

Roelfsema, M.G. and Prins, H.A. (1997) lon channels in guard cells of Arabidopsis thaliana (L.) Heynh. Planta, 202, 18-27.

Romano, L.A., Miedema, H. and Assmann, S.M. (1998) $\mathrm{Ca}^{2+}$-permeable, outwardly-rectifying $\mathrm{K}^{+}$channels in mesophyll cells of Arabidopsis thaliana. Plant Cell Physiol. 39, 1133-1144.

Rowley, C.N. and Roux, B. (2013) A computational study of barium blockades in the KcsA potassium channel based on multi-ion potential of mean-force calculations and free energy perturbation. J. Gen. Physiol. 142, 451-463.

Sokolovski, S. and Blatt, M.R. (2004) Nitric oxide block of outward-rectifying $\mathrm{K}^{+}$channels indicates direct control by protein nitrosylation in guard cells. Plant Physiol. 136, 4275-4284.
Sutter, J.U., Campanoni, P., Tyrrell, M. and Blatt, M.R. (2006) Selective mobility and sensitivity to SNAREs is exhibited by the Arabidopsis KAT1 $\mathrm{K}^{+}$channel at the plasma membrane. Plant Cell, 18, 935-954.

Sutter, J.U., Sieben, C., Hartel, A., Eisenach, C., Thiel, G. and Blatt, M.R (2007) Abscisic acid triggers the endocytosis of the Arabidopsis KAT1 K+ channel and its recycling to the plasma membrane. Curr. Biol. 17, 13961402.

Tester, M. (1990) Plant ion channels: whole-cell and single-channel studies. New Phytol. 114, 305-340.

Thiel, G. and Blatt, M.R. (1991) The mechanism of ion permeation through $\mathrm{K}^{+}$channels of stomatal guard cells voltage-dependent block by $\mathrm{Na}^{+}$. J. Plant Physiol. 138, 326-334.

Thiel, G., MacRobbie, E.A.C. and Blatt, M.R. (1992) Membrane transport in stomatal guard cells: the importance of voltage control. J. Membr. Biol. 126, 1-18.

Thiel, G., Blatt, M.R., Fricker, M.D., White, I.R. and Millner, P.A. (1993) Modulation of $\mathrm{K}^{+}$channels in Vicia stomatal guard cells by peptide homologs to the auxin-binding protein C-terminus. Proc. Natl Acad. Sci. USA, 90, 11493-11497.

Vergani, P., Miosga, T., Jarvis, S.M. and Blatt, M.R. (1997) Extracellular K ${ }^{+}$ and $\mathrm{Ba}^{2+}$ mediate voltage-dependent inactivation of the outward-rectifying $\mathrm{K}^{+}$channel encoded by the yeast gene TOK1. FEBS Lett. 405, 337-344.

Vergani, P., Hamilton, D., Jarvis, S. and Blatt, M.R. (1998) Mutations in the pore regions of the yeast $\mathrm{K}^{+}$channel $\mathrm{YKC} 1$ affect gating by extracellular $\mathrm{K}^{+}$. EMBO J. 17, 7190-7198.

Villalba, J.M., Lutzelschwab, M. and Serrano, R. (1991) Immunocytolocalization of plasma membrane $\mathrm{H}^{+}$-ATPase in maize coleoptiles and enclosed leaves. Planta, 185, 458-461.

Wang, Y. and Blatt, M.R. (2011) Anion channel sensitivity to cytosolic organic acids implicates a central role for oxaloacetate in integrating ion flux with metabolism in stomatal guard cells. Biochem. J. 439, 161-170.

Wang, Y., Papanatsiou, M., Eisenach, C., Karnik, R., Williams, M., Hills, A. Lew, V.L. and Blatt, M.R. (2012) Systems dynamic modelling of a guard cell $\mathrm{Cl}^{-}$channel mutant uncovers an emergent homeostatic network regulating stomatal transpiration. Plant Physiol. 160, 1956-1972.

Yuasa, K., Toyooka, K., Fukuda, H. and Matsuoka, K. (2005) Membrane-anchored prolyl hydroxylase with an export signal from the endoplasmic reticulum. Plant J. 41, 81-94.

Zilly, F.E., Halemani, N.D., Walrafen, D., Spitta, L., Schreiber, A., Jahn, R and Lang, T. (2011) $\mathrm{Ca}^{2+}$ induces clustering of membrane proteins in the plasma membrane via electrostatic interactions. EMBO J. 30, 1209-1220.

Zonia, L. and Munnik, T. (2007) Life under pressure: hydrostatic pressure in cell growth and function. Trends Plant Sci. 12, 90-97. 